\title{
The state of South African internships: A national survey against HPCSA guidelines
}

\author{
S Bola, E Trollip, F Parkinson \\ Eudiet Trollip is a medical officer at Victoria Hospital, Cape Town, South Africa. Summy Bola and Fran Parkinson are surgical registrars in the UK.
}

Corresponding author: S Bola (sbola@nhs.net)

\begin{abstract}
Background. Medical internship is designed to bridge the gap between the theoretical knowledge learned as a student and the skills required as a competent medical practitioner. In South Africa (SA) it is a 2-year structured programme incorporating experience in key domains of medicine selected by the Health Professions Council of South Africa (HPCSA). HPCSA guidelines state that the clinical experience should include teaching, supervision and competency in selected logbook procedures. After concerns were raised over some accredited intern facilities, we investigated whether these guidelines were being met for interns across SA.

Methods. An electronic survey was sent to 150 SA doctors who had completed their internship between 2010 and 2013. The questions covered supervision, workload and rest, teaching and perception of patient safety. All responses were anonymous and there was opportunity to comment at the end of each question.

Results. The respondents $(n=90)$ included graduates from all eight SA medical schools. Supervision was ranked as the aspect of internship that respondents would change the most, with $33.0 \%$ performing an interventional procedure for the first time without supervision and $25.6 \%$ experiencing an adverse event where senior help was not available. More than half the interns had an entire shift supervised by a medical officer with less than 3 years' clinical training in that specialty.

Conclusions. This survey identified deficiencies of supervision as directed by the HPCSA. It also highlighted difficulties with workload and teaching opportunities. A significant proportion of interns did not feel that patients were safe under their care. A national annual HPCSA survey would highlight hospitals where closer investigation may be required.
\end{abstract}

S Afr Med J 2015;105(7):535-539. DOI:10.7196/SAMJnew.7923

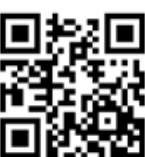

The South African (SA) medical internship is designed to bridge the gap between the knowledge and skills learned at university and the clinical skills set required for the community service officer (CSO) year, which may involve working as an independent medical practitioner in a rural area. The internship was introduced in 1950 by the South African Medical and Dental Council, which was responsible for overseeing the registration and conduct of medical practitioners. It is now regulated by the Health Professions Council of South Africa (HPCSA). ${ }^{[1]}$

In 2005, after identifying a deficiency in all-round competence among doctors completing a 1-year internship programme, ${ }^{[2]}$ the internship was changed to a 2-year structured curriculum involving rotations in key medical domains chosen by the HPCSA (Table 1) and a syllabus of logbook requirements.

Recognising the significant transition from medical school, accredited internship hospitals are charged with the responsibility of providing suitable supervision, guidance and evaluation of clinical work in medical and surgical rotations. Each accredited facility has an assigned curator to act as a spokesperson for the newly qualified doctors and to assist the hospital chief executive (or equivalent) in the role of organising orientation and ensuring continuous evaluation of clinical skills. The HPCSA provides guidelines and restrictions on the level of clinical work a medical intern can carry out independently. Selected examples are listed in Table 2. ${ }^{[3]}$

Acknowledging that working without sufficient supervision compromises patient safety and promotes incorrect learning, the HPCSA guidelines are there to protect both the patient and the newly qualified doctor. For this reason, interns are not permitted to undertake locum work or be employed at unaccredited facilities. Despite this there have been reports of inadequate supervision, as a result of which the HPCSA has rescinded accreditation of some previously accredited facilities. ${ }^{[4]}$ This study aimed to investigate whether HPCSA guidelines are being complied with in accredited institutions across SA.

\section{Methods}

A pilot 30-question electronic survey was designed to cover topics similar to those addressed in the annual National General
Medical Council training survey in the UK, which is a validated survey adopted and developed to ascertain trainee perception of compliance with General Medical Council standards. ${ }^{[5]}$ The pilot topics included clinical supervision, educational supervision (teaching), handover, induction and patient safety concerns. The questions directly reflected standards from the HPCSA Handbook on Internship Training. ${ }^{[3]}$ The questionnaire was electronically sent to a pilot group of ten CSOs who had completed their internship in December 2013. The feedback from the pilot indicated

\begin{tabular}{lr}
$\begin{array}{l}\text { Table 1. The recommended SA } \\
\text { internship programme }\end{array}$ \\
\hline Specialty \\
\hline General medicine & 4 months \\
Orthopaedics & 2 months \\
Anaesthetics & 2 months \\
Obstetrics and gynaecology & 4 months \\
Family medicine or general practice 3 months \\
Psychiatry & 1 month \\
Paediatrics & 4 months \\
General surgery & 4 months
\end{tabular}




\section{Table 2. Selected examples of HPCSA guidelines for internship training}

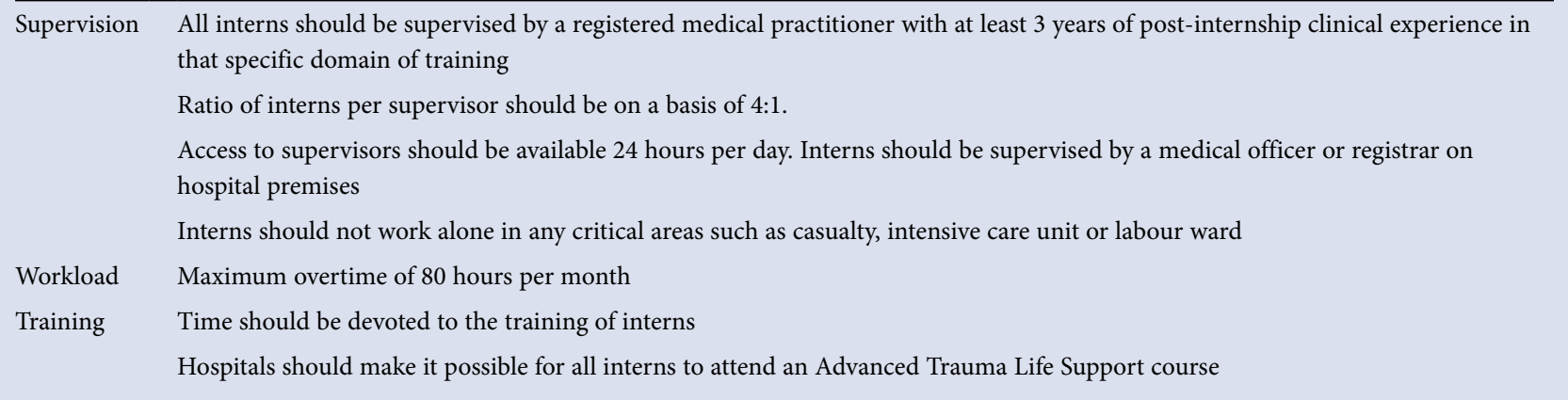

lesser concerns for handover and induction guidelines but greater concerns regarding supervision during internship and patient safety. Feedback was also received regarding the length of the survey, which was reduced to 20 questions reflecting the following: (i) levels of supervision; (ii) workload and overtime; (iii) teaching and training; and (iv) perception of patient safety under the respondent's care.

This survey was sent to 150 doctors who had completed their internship in December 2013. Email addresses were obtained through the hospital administrations of HPCSA-accredited facilities and from university alumni networks (we were unable to obtain more than 150 email addresses, owing to a poor response from hospital administrations). The survey was open from 1 January 2014 to 1 March 2014, to limit recall bias. All contacts were emailed a reminder 2 weeks before the survey closed. Non-responders were not followed up.

We aimed to reach graduates from all SA medical schools. All responses were anonymous and there was an opportunity to comment at the end of each question. Eleven surveys were excluded because respondents had experienced delays in completing their internship, either through choice (e.g. unpaid leave) or from failing to meet specialty requirements in a rotation, therefore requiring extra training time.

\section{Results}

The response rate was $60.0 \%(n=90)$, with responses from interns who had graduated from all eight SA medical schools (Fig. 1) and had received internship training across 24 teaching hospitals.

\section{Supervision and safety}

A third (33.0\%) of respondents reported that they had performed an interventional or surgical procedure for the first time without supervision from start to finish. For 5 respondents, this occurred on more than one occasion. These procedures are listed in Table 3.

Anaesthetics was listed as the most supervised specialty, and medicine and family medicine as the least supervised (Fig. 2). Contrary to HPCSA recommendations, over half of the interns (55.5\%) reported that they were regularly supervised by a medical practitioner with less than 3 years' post-graduation experience. In addition, $25.6 \%$ had experienced an event where they required senior help but the senior was not on the hospital premises.

\section{Workload}

While the majority of respondents (88.9\%) felt that their medical school had prepared them for internship, some commented about not being prepared for the responsibility or the workload. Surgery, medicine and obstetrics and gynaecology most frequently required interns to work outside their contracted hours; this was consistent across the 24 teaching hospitals (Fig. 3).

When asked why they worked outside contracted hours, $74.4 \%$ attributed it to staff shortages, a heavy patient load or little help from

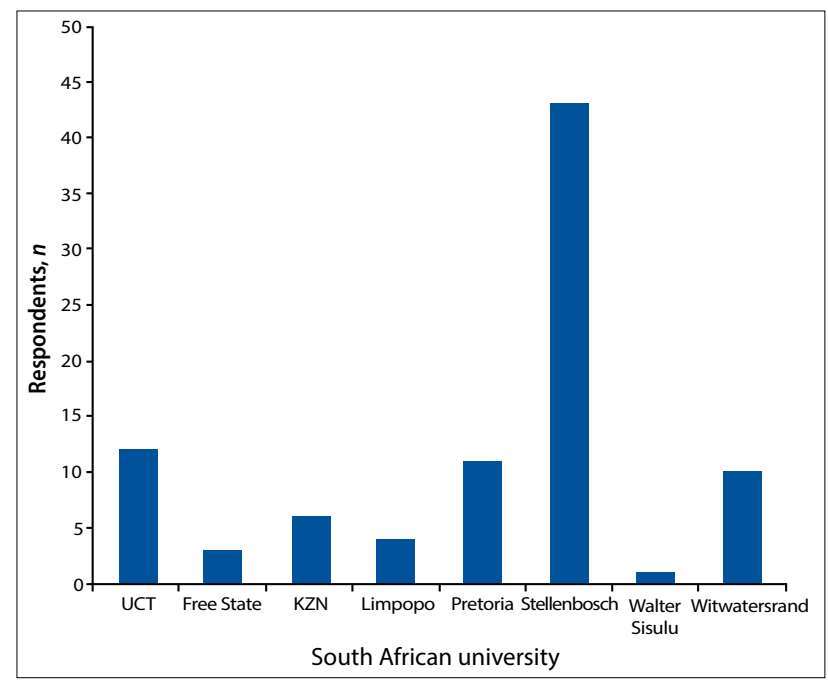

Fig. 1. Medical schools from which the respondents had graduated. (UCT = University of Cape Town; KZN = University of KwaZulu-Natal.)

Table 3. Procedures performed by interns without supervision throughout the procedure

\begin{tabular}{ll}
\hline Procedure & $\begin{array}{l}\text { Interns performing procedure } \\
\text { for the first time without } \\
\text { supervision, } \boldsymbol{n}\end{array}$ \\
\hline Chest drain & 9 \\
Central venous line & 5 \\
Lumbar puncture & 4 \\
Administration of local & 4 \\
anaesthetic & \\
Umbilical vein catheter & 3 \\
Suprapubic catheterisation & 3 \\
Lymph node biopsy & 2 \\
Bone marrow aspirate & 2 \\
Shoulder reduction & 2 \\
Amputation of finger & 1
\end{tabular}

nursing colleagues (Fig. 4). Other reasons included poor personal organisation, uncertainty about patient management, and difficulty in obtaining results of investigations.

The typical on-call shift consisted of 24 hours on call followed by a half day of normal duties; $65.6 \%$ of respondents said that they frequently had to stay at work after this shift finished, meaning 


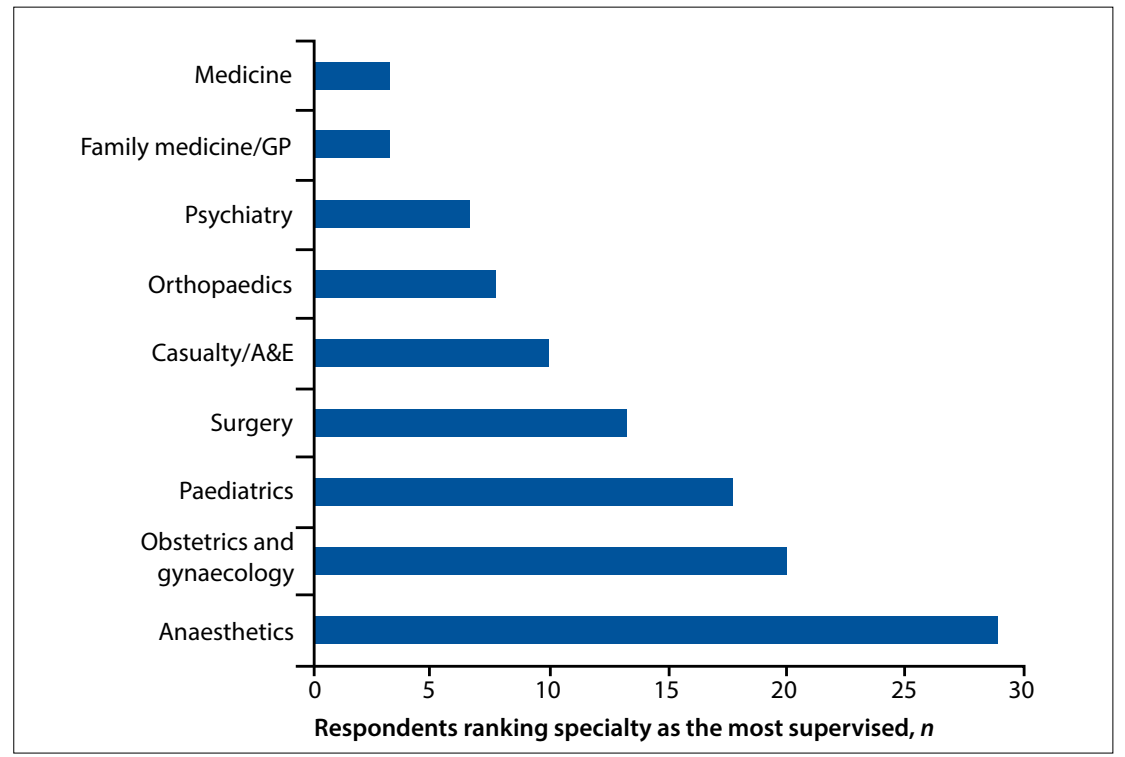

Fig. 2. Repondents' perceptions of the most supervised specialties. ( $A \circlearrowleft E=$ accident and emergency; $G P=$ general practice.)

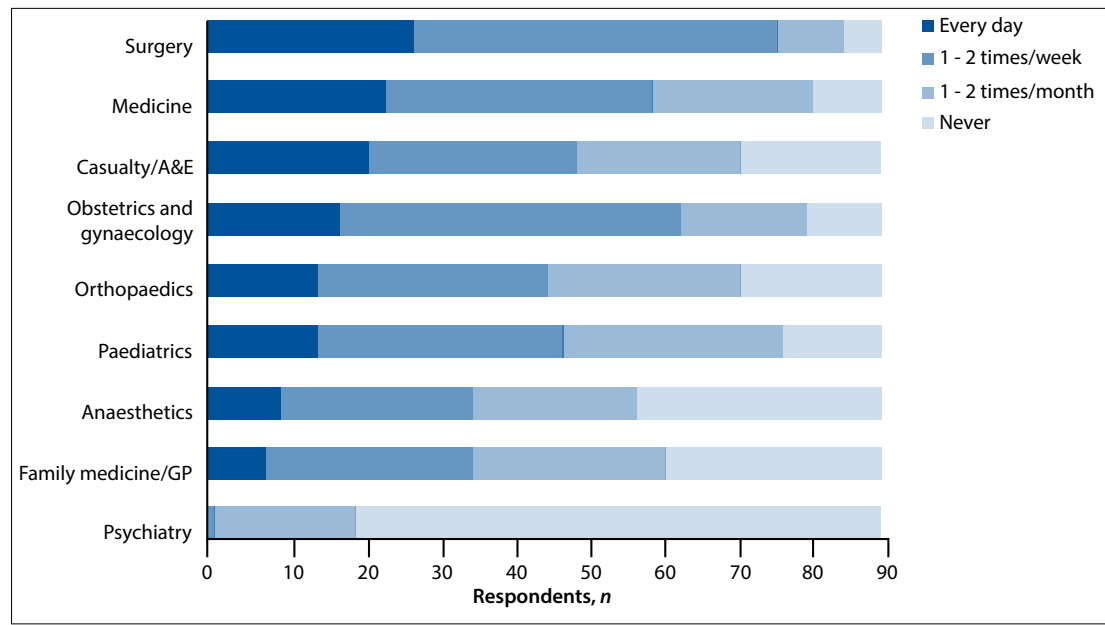

Fig. 3. Responses to question 'How often did you work outside your contracted hours?' (A®E = accident and emergency; $G P=$ general practice.)

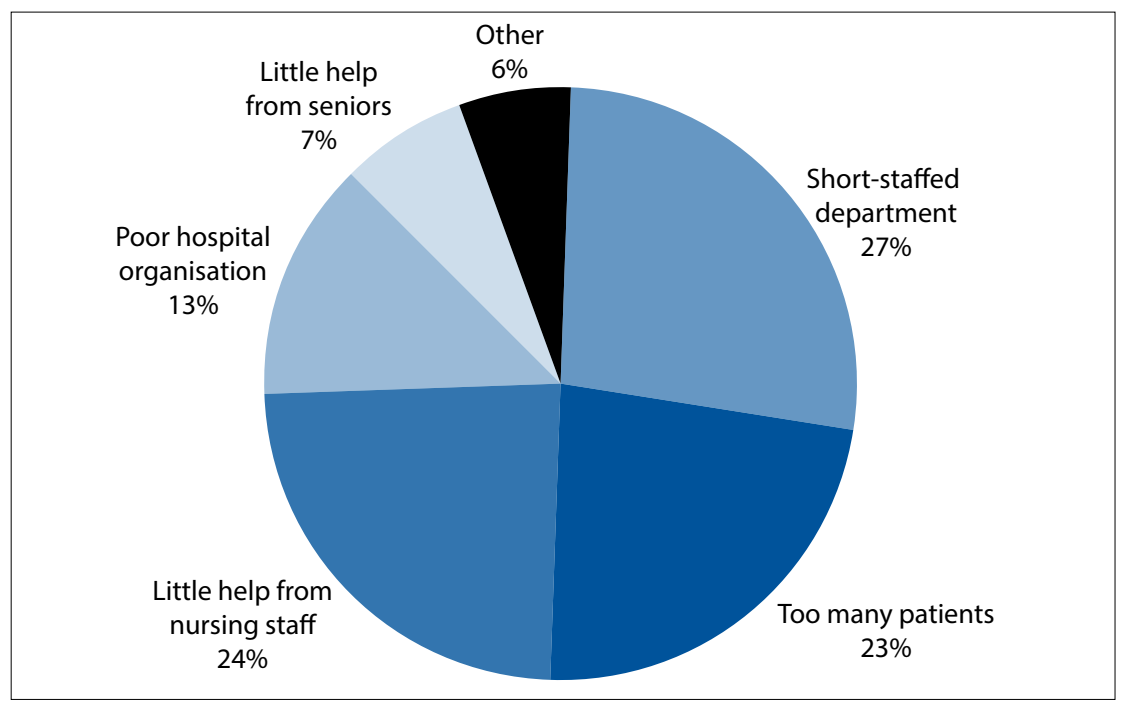

Fig. 4. Responses to question 'Why do you think you worked outside your contracted hours?' ('Other' = poor personal organisation, delayed scan/blood results, uncertainty with management plan.) that the majority of interns were frequently working a shift of more than 30 hours in duration and exceeded the recommended 80 hours of overtime per month.

When asked about their daily tasks, respondents stated that the majority of daily working hours were spent undertaking basic procedures such as venepuncture, gaining intravenous access and inserting catheters.

\section{Teaching}

Anaesthetics, orthopaedics, obstetrics and gynaecology and surgery scored the highest in terms of frequency of departmental teaching, with 33 participants (36.7\%) stating that they received scheduled teaching daily or multiple times in the week. Casualty and family medicine were ranked lowest for teaching, with 18 (20.0\%) reporting teaching sessions as 'rare' or 'never.'

\section{Perception of patient safety}

With regard to whether they had ever made a mistake on a drug chart (Fig. 5), most respondents commented that their errors were picked up by the nursing staff before the incorrect drug or dose was given. The most common drug errors were antibiotic dosage errors and prescribing medication to which the patient had an established allergy.

The survey asked respondents if they had ever felt that patient safety was compromised under their care as an intern. Only $22.2 \%$ felt that patient safety was never compromised, and $4.4 \%$ reported feeling that patient safety was compromised on a 'daily' basis. The most common reason for the perception of poor patient safety was poor supervision $(n=17)$, which led to uncertainty in medical decisionmaking. The second most common reason was shortage of medical resources $(n=12)$.

\section{The final results}

By the end of the 2-year internship programme, 73 respondents $(81.1 \%)$ felt prepared for their CSO year. When asked what single aspect of the internship they would choose to change (Fig. 6), the majority selected 'More supervision'.

\section{Discussion}

Medical internships are designed to provide the foundation for future independent clinical work. Despite the intern programme having been lengthened to 2 years in 2005, deficiencies in supervision and safety exist across all rotations and hospitals. The HPCSA sets standards for the supervision and workload of interns, but our survey demonstrates non-compliance with the HPCSA standards for intern clinical work. 


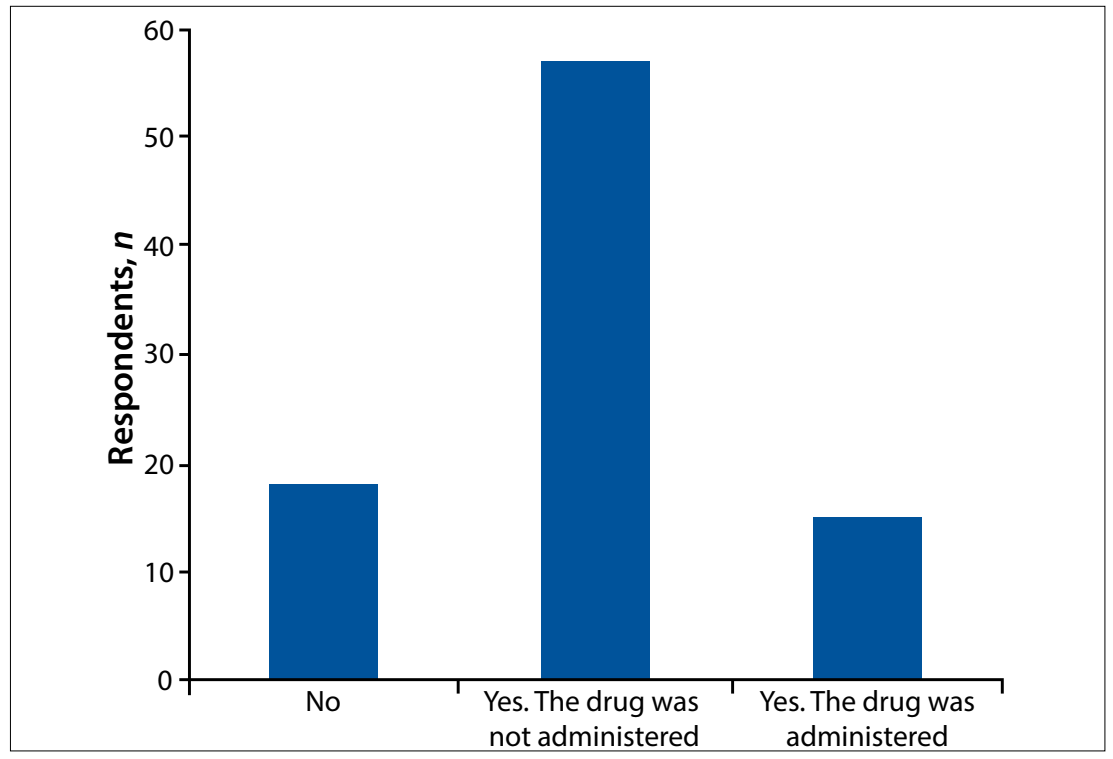

Fig. 5. Responses to question 'Have you ever made a mistake on a drug chart?'

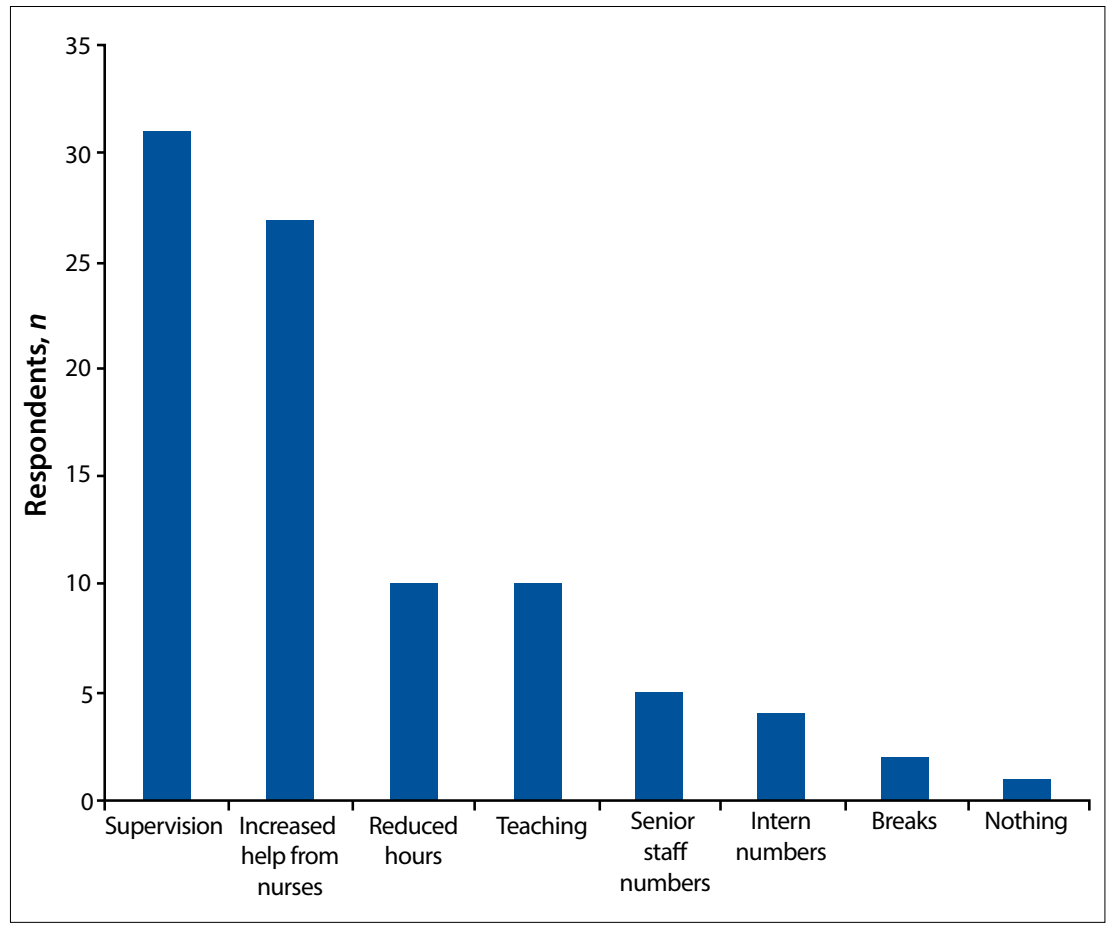

Fig. 6. Responses to question 'What aspect of your internship would you most like to change?'

In particular, there was significant failure in providing supervision of interns performing interventional procedures for the first time. This has obvious safety implications for both the patient, who is receiving an inadequate level of care for procedures that carry the potential for morbidity and mortality, ${ }^{[6]}$ and for the intern, who may learn and repeat the procedure incorrectly or experience an adverse event, which is not only traumatic but carries the risk of medicolegal action. ${ }^{[7]}$ The HPCSA clearly states that all doctors must Acknowledge the limits of their professional knowledge and competence. ${ }^{\left[{ }^{[8]}\right.}$ However, there may be pressure on interns to carry out procedures for which the guidelines are blurred when there are no seniors available. Previous qualitative studies have described internship concerns regarding teaching, workload and supervision..$^{[9]}$ This survey demonstrates that patient safety was the biggest concern for a large majority of respondents.

There was non-compliance to rules set out by the HPCSA with regard to the seniority of the intern supervisor, with more than half of the respondents reporting supervision from another intern or a CSO on a regular basis.
This situation has been reported in a previous study, where the procedural skills gained by the intern were recognised as inferior, ${ }^{[10]}$ and is not a surprising occurrence considering the staff shortages in many health departments across SA. As SA doctors are able to practise in an unsupervised environment after their CSO year (or even during this year in many rural settings), other provisions should be made to ensure that internship provides a protected working space to exercise clinical skills under supervision (with feedback) to ensure that patients are treated in a safe and appropriate manner. Although the majority of respondents felt prepared for their CSO year, which is in keeping with other research ${ }^{[11]}$ a largely unsupervised internship turning into a completely unsupervised CSO year will promote a cycle of confident incompetence ${ }^{[12]}$ in medical decision-making and compromise patient safety further.

According to the SA National Department of Health, 'The main objective of Community Service is to ensure improved provision of health services to all the citizens of our country. ${ }^{[13]}$ However, it is important to note that the rural areas only have each CSO for one year, with very few staying longer; the majority make plans to enter private sector medical work or travel abroad. ${ }^{[14-15]}$ At present, only $30 \%$ of all doctors undertake public sector duties for the vast majority of SA citizens who cannot afford private healthcare. ${ }^{[16]}$ It is therefore important to promote other factors that may influence hospital selection and public sector work, such as job satisfaction, manageable workload, teaching and career advancement opportunities.

Across all hospitals, the anaesthetics rotation was ranked the most supervised specialty and also scored highly in terms of teaching and workload. This may reflect the fact that the rotation is too short to acquire competency for independent clinical work.

The primary responsibility for the interns and their training rests with the chief executive and the senior medical staff of the accredited hospital or facility, and it is quite clear that reducing workload will in turn leave more potential time for teaching. To address the workload discrepancies across the specialties, a number of solutions can be suggested to relieve the interns of tasks that can be undertaken by allied health professionals.

\section{Recommendations}

For the clinical manager:

- Establish a phlebotomy service.

- Use hospital assistants to help nursing staff with non-medical daily tasks such as patient clothing, simple dressings and bed linen changes, to help nursing staff utilise their skills set and free the time of the intern. 
- Have ward clerks to distribute and chase up patient results and formulate patient lists.

- Ensure weekly protected intern teaching that is separate from departmental teaching to ensure continued learning throughout the year and to cover generic topics such as drug prescribing and technical skills.

- Offer pastoral support, assigning each intern a clinical supervisor for the 2-year programme who is separate to the intern curator.

- Employ a co-ordinator to arrange patient transport and discharge.

For the HPCSA:

- Increase the number of medical officer posts per internshipaccredited hospital.

- Undertake annual national training surveys to identify centres where interns are subject to inadequate levels of supervision and teaching.

\section{Study limitations}

As with any survey, self-reported data are subject to recall bias and subjectivity. It was difficult to find contact details for doctors who had completed their internship, as many hospitals did not agree to distribute the survey or no longer kept records for previous employees. Because we therefore relied heavily on university alumni networks to distribute the web link for the survey, respondents were mostly graduates from the Western Cape, imposing a potential bias.

The study did not aim to provide objective validation of doctor training, like the GMC survey on which it is based, but to provide an insight into how HPCSA guidelines are not being met or may not represent realistic goals. As the pilot group requested fewer questions, we did not collect data on important areas such as intern induction and bullying, which would be addressed by developing a formal national survey.

\section{Conclusion}

Medical education for interns is based on the apprenticeship model of 'learning on the job', and supervisors should be available to assess skills and gradually increase responsibility according to interns' developing abilities. According to the survey results, this model is being grossly neglected, with particular concern about supervision. Despite staff shortages in the SA health service and a maldistribution of private and public sector workers, interns must receive the correct clinical supervision, teaching and inspiration to encourage them to continue with public sector work.

1. De Vries H, Sanderson P, Barbara J, et al. International Comparison of Ten Medical Regulatory Systems. Commissioned by the UK General Medical Council. Cambridge, UK: Rand Corporation, 2009:121-133.

2. Cameron D, Blitz J, Durrheim D. Teaching young docs old tricks - was Aristotle right? An assessment of the skills training needs and transformation of interns and community service doctors working at a district hospital. S Afr Med J 2002;92(4):276-278.

3. Medical and Dental Professions Board, Health Professions Council of South Africa, Handbook on Internship Medical and Dental Professions Board, Health Professions Council of South Africa, Handbook on Internship
Training. Guidelines for Interns, Accredited Facilities and Health Authorities [Brochure]. Pretoria: HPCSA, 2013. Training. Guidelines for Interns, Accredited Facilities and Health Authorities [Brochure]. Pretoria: HPCSA, 2013.
Medical and Dental Professions Board South Africa. Medic Dent News 2012 - HPCSA removes 4. Medical and Dental Professions Board South Africa. Medic Dent News 2012 - HPCSA removes
interns from hospital. http://www.hpcsa.co.za/Uploads/editor/UserFiles/downloads/publications/ newsletters/mdb/medicdent_newsletter_april_2012.pdf (accessed 12 November 2014).

5. General Medical Council. National training surveys: Background. http://www.gmc-uk.org/education/ survey_background.asp (accessed 10 January 2015).

6. Maritz D, Wallis L, Hardcastle T. Complications of tube thoracostomy for chest trauma. S Afr Med J 2009;99(2):114-117.

7. Medical Protection Society South Africa. Junior Doctor 2013;4(1). http://www.medicalprotection.org/docs/ default-source/pdfs/sa-junior-doctor-pdfs/may-2013.pdf?sfvrsn=2 (accessed 12 November 2014).

8. Health Professions Council of South Africa. General Ethical Guidelines for the Health Care Professions. Booklet 1 (2008). www.hpcsa.co.za/downloads/conduct ethics/rules/generic ethical_ rules/ booklet_1_guidelines_good_prac.pdf (accessed 12 November 2014).

9. Sein N Sein N, Kumbo J. Determinants of effective medical intern training at a training hospital in North West Province,

10. Jaschinski J, de Villiers MR. Factors influencing the development of practical skills of interns working in regional hospitals of the Western Cape province of South Africa. S Afr Fam Pract 2008;50(1):70a-70d. [http://dx.doi.org/10.1080/20786204.2008.10873676]

11. Nkabinde TC, Ross A, Reid S, Nkwanyana NM. Internship training adequately prepares South African medical graduates for community service - with exceptions. S Afr Med J 2013;103(12):930-934. [http://dx.doi.org/10.7196/samj.6702]

12. Mateau TM, Wynne G, Kaye W, Evans TR. Resuscitation: Experience without feedback increases confidence but not skill. BMJ 1990;300(6728):849-850 [http://dx.doi.org/10.1136/bmj.300.6728.849]

13. Reid S. Compulsory community service for doctors in South Africa - an evaluation of the first year. S Afr Med J 2001;91(4):329-336.

14. Hagopian A, Thompson MJ, Fordyce M, Johnson KE, Hart LG. The migration of physicians from subSaharan Africa to the United States of America: Measures of the African brain drain. Hum Resour Health 2004;2(1):17. [http://dx.doi.org/10.1186/1478-4491-2-17]

15. Centre for Rural Health, University of Natal. Reid S. Community service for health professionals 2002. http://reference.sabinet.co.za/webx/access/electronic_journals/healthr/healthr_2002_a10.pdf (accessed 30 Norese.sab

16. Health Economics and HIV \& AIDS Research Division (HEARD). Human Resources of Health: A Needs and Gaps Analysis of HRH in South Africa. Durban: HEARD, University of KwaZulu-Natal, 2009.

Accepted 11 June 2015. 